\title{
Course recommendation system using fuzzy logic approach
}

\author{
Mohd Suffian Sulaiman ${ }^{1}$, Amylia Ahamad Tamizi ${ }^{2}$, Mohd Razif Shamsudin ${ }^{3}$, Azri Azmi $^{4}$

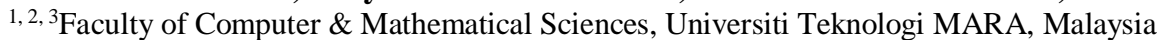 \\ ${ }^{4}$ Razak Faculty of Technology and Informatics, Universiti Teknologi Malaysia, Malaysia
}

\begin{tabular}{l}
\hline \hline Article Info \\
\hline Article history: \\
Received May 26, 2019 \\
Revised Jun 24, 2019 \\
Accepted Jul 9, 2019
\end{tabular}

Keywords:

Fuzzy logic

Interest

Mamdani

Recommendation system

Rules

Skill

\begin{abstract}
Course selection is a key for success in student's academic path. In today's education environment, various courses offered by different academic institutions required the students to explore the course outline manually. Most of them are lacking in knowledge, having dilemma and making blind selections to choose the right course. Therefore, it is essential to have a course recommendation to provide guidance to a student to choose the course related with their interest and skill. This paper proposed to develop a course recommendation system using fuzzy logic approach. The development methodology of this system involves several phases include requirements planning, user design and construction for prototyping, testing and cutover. This study used the fuzzy rules technique in order to calculate each associated student's skill and interest level based on Mamdani fuzzy inference system method. Then, the rules will generate final outcome which recommend the suitable course path and provide the details to a user based on their course test. The result shows the functionality of this system has been achieved and works well. This study is significantly helping the students to choose their course based on the interest and skill.
\end{abstract}

Copyright $(2020$ Institute of Advanced Engineering and Science. All rights reserved.

\section{Corresponding Author:}

Mohd Suffian Sulaiman,

Computer Science Centre of Studies,

Faculty of Computer \& Mathematical Sciences,

Universiti Teknologi MARA,

40450 Shah Alam, Selangor Darul Ehsan, Malaysia.

Email: suffian@tmsk.uitm.edu.my

\section{INTRODUCTION}

A key of a student success in their tertiary education is choosing the right course and they need to have a deep interest in each course that has been chosen. To get the exact course, students should recognize their potential, skills and the academic result. However, they are not mature enough to decide by himself in his early life [1-2]. Almost of them lack of knowledge to get the information about a few courses and that make them blindly choose the course.

The main purpose of this study is to help the student that are often facing a dilemma and confusing in deciding to choose the right course. Choosing a right course and study in formative years is very important as their future depends on one decision. Therefore, a course recommendation system is needed to assist the student to choose the right course. It can provide a solution to help the student to get the target appropriate result.

The recommendation system is known as an intelligent system, which can suggest the user to get the best target appropriate result based on user information analysis and user interest analysis [3-5]. According to Yang et al. (2014) they also proved that the recommendation system is the powerful way to solve similar problems. The highest number of the users interact with the system, it will make the system to get more information about him, and the consequence will become a new data, then it leads to fulfill others aim more better [7-9]. There are several previous recommendation system that have been developed for certain domain. 
Thiel (2018) developed the career test web-based recommendation system. This system recommends the list of careers suitable for them based on their skills, abilities and personalities. Each of the questions using the image to test the student by choices either like or dislike. The advantage of this system is the result displayed a pie chart and provide some details about the career suggestion by a system and also provides some details for each user's personalities. Hence, it makes the students easier to get some knowledge. However, the weakness of this system is only use one answering style which is like or dislike. It should provide multiple style to answer the question such as yes or no, percentage and scale.

Another example of recommender system developed by Educations Media Group that focuses for a student to get an appropriate result about their suggestion course [11]. This recommendation system provides 35 questions to test a student based on student's interest. The system provides the result by displaying the statistic and explained more about the top recommender. It also gives a few course suggestions for a student. Thus, they can get many other choices for themselves. However, the deficiency for this recommender system is similar like the system in Thiel (2018). The result can be more relevant if the system also depends on their subjects that have been taken before.

Grewal \& Kaur (2015) has similar works with our proposed study because it also assist the student to find an appropriate course and future job. The result of this system provides the most appropriate courses and job for students. A student selects the subject that they like and enter the previous mark. Then the system will suggest top-two basis of subjects that suitable for a student. Final suggestion on the basis of overall marks and job is generated. The advantages of this system is the result will be displayed in a table and a student can print out these suggestions, log in to the system and edit the mark to get a new suggestion. However, the input only consider one scope of subjects only and not based on the interest of the student.

\section{RESEARCH METHOD}

Fuzzy Logic is part of Artificial Intelligence (AI) that tries to solve the problem depart by using human intelligence[13-15]. Basically, Fuzzy Logic is composed of four functional blocks as shown in Figure 1 [16-18]. This architecture shows how the data go through to process the input crisp from user until the system give the output. Data are formalized to be stored in knowledge based. The process from input crisp until output crisp are involved user fuzzification of the input variables, inference engine which consist of rule evaluation and aggregation and defuzzification [19].

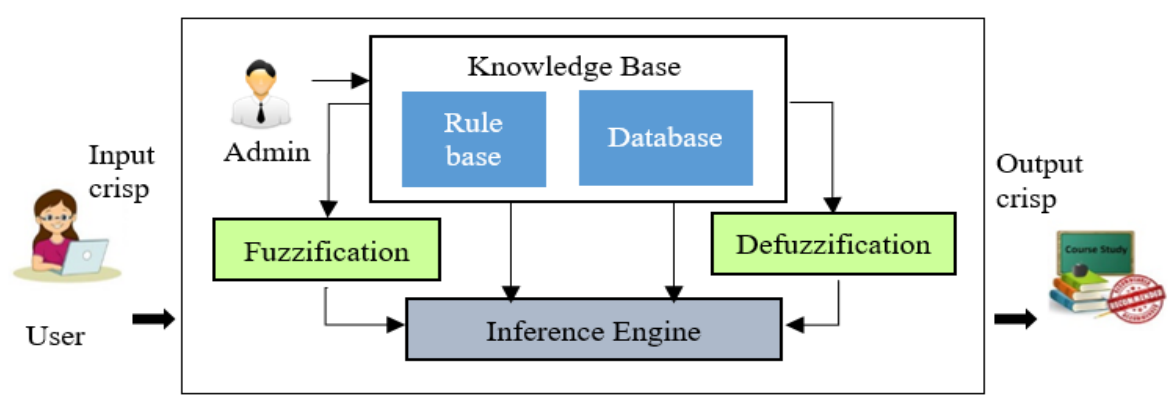

Figure 1. Fuzzy logic process architecture

\subsection{Fuzzification}

The first phase is creating the fuzzification process including the input crisp from a student [20]. The input for this study can be categorized into two parts which are skill and interest. The data about skill is contributed from the eight courses from diploma results as shown in Table 1 which can be categorized as programming, problem solving, computer and data analysis skills. While, the interest part is based on the twelve questions provided as shown in Table 2 which can be categorized based on programming, critical thinking, organizing information, practical work, data processing and networking. The input of skill and interest is collected based on the consultation of domain expert from Jawatankuasa Kecil Kurikulum Pusat Pengajian (JKKPP), Faculty of Computer \& Mathematical Sciences (FSKM), Universiti Teknologi MARA (UiTM), Shah Alam, Selangor [21].

The student need to answer all these questions as shown in Table 1 and 2. The input in Table 1 and Table 2 then will transform into linguistic variable as shown in Table 3 and Table 4 respectively. When the 
question structure of the user is successfully designed, interest of the user test results will be sent to the next process where student should have several answer choices. Student will enter his or her interest level which are 'No', 'Maybe' or 'Yes'. The questionnaire questions is separated and grouped it into several types of interest classes. With this in mind, the system will calculate and classify the type of interest of the students to either weak, medium or good based on the range that is shown in Table 3 and Table 4. The range in between 0 to 10 are separated into three parts with overlapping graph that follows the appropriate range of values stated as weak, medium and good.

Table 1. Input for Skill Part

\begin{tabular}{cccc}
\hline No. & Course Code & Course Name & Skills \\
\hline 1 & CSC138 & Structured programming & Programming (S1) \\
2 & CSC248 & Fundamental of data structure & Problem solving (S2) \\
3 & QMT200 & Probability and statistic & \\
4 & MAT233 & Calculus II & Computer (S3) \\
5 & CSC204 & Approach of operating system & Data analysis (S4) \\
6 & ITT300 & Introduction of data communication \& networking & \\
7 & IT232 & Introduction to database & \\
8 & IT332 & Information System & \\
\hline
\end{tabular}

Table 2. Input for Interest Part

\begin{tabular}{lll}
\hline No. & Questionnaire & Interest \\
\hline 1 & Do you eager to learn more about programming language (e.g. Java, C, C++, PHP and ASP)? & Programming (I1) \\
2 & You have just been given a complex task to code. Do you have interest to solve the task? & \\
3 & When you face unexpected problem, do you like to handle it and look at different ways to solve it? & Critical thinking (I2) \\
4 & Do you have ever image to create a creative solutions in information technology? & Organizing \\
5 & Do you have an interest to translating client requirement into highly specified project brief? & information \\
6 & Do you think that working in group can help you to organize the client requirement information & (I3) \\
7 & easily? & Do you have an interest work about routing and switching? \\
8 & Do you have an interest and courage to perform the practicality study about network courses? & Datical work (I4) \\
9 & Do you have an interest to handle and process large amount of unstructured data to develop & Data processing (I5) \\
10 & intelligent systems applications? & Do you have an interest to manage and process large amount of data using various intelligent \\
11 & techniques? & Do you like to learn about how computer hardware and software operates? \\
12 & Do you like to learn and have better knowledge about computer networking? & Networking (I6)
\end{tabular}

The overlapping graph act as a gray area where the fuzzy inference needs to decide which overlapping graph actually will be calculated as the output of the inference. This will happen as the process of the rule evaluation is explained in the next subsection. For an example, the range for programming skill is 3.3. Then the user linguistic variable be overlapping with either weak or medium graph. So, to solve such problem like this, the inference will choose the one that has a higher fuzzy value which is medium.

Table 3. Linguistic Variable for Skill

\begin{tabular}{|c|c|c|c|c|}
\hline No. & $\begin{array}{l}\text { Input / } \\
\text { Courses }\end{array}$ & Skills & Linguistic variable & Range \\
\hline 1 & CSC138 & Programming (S1) & $\{$ Weak, Medium, Good $\}$ & $\{0-3.5,3.2-6.5,6.2-10\}$ \\
\hline 2 & CSC248 & & & \\
\hline 3 & QMT200 & Problem Solving (S2) & $\{$ Weak, Medium, Good $\}$ & $\{0-3.5,3.2-6.5,6.2-10\}$ \\
\hline 4 & MAT233 & & & \\
\hline 5 & CSC204 & Computer (S3) & $\{$ Weak, Medium, Good $\}$ & $\{0-3.5,3.2-6.5,6.2-10\}$ \\
\hline 6 & ITT300 & & & \\
\hline 7 & ITS232 & Data Analysis (S4) & $\{$ Weak, Medium, Good $\}$ & $\{0-3.5,3.2-6.5,6.2-10\}$ \\
\hline 8 & ITS332 & & & \\
\hline
\end{tabular}


Table 4. Linguistic variable for interest

\begin{tabular}{|c|c|c|c|c|}
\hline No. & Input / Questions & Interest & Linguistic variable & Range \\
\hline 1 & $\mathrm{Q} 1$ & Programming (I1) & $\{$ Weak, Medium, Good $\}$ & $\{0-3.5,3.2-6.5,6.2-10\}$ \\
\hline 2 & Q2 & & & \\
\hline 3 & Q3 & Problem Solving (I2) & $\{$ Weak, Medium, Good $\}$ & $\{0-3.5,3.2-6.5,6.2-10\}$ \\
\hline 4 & Q4 & & & \\
\hline 5 & Q5 & Organizing Information (I3) & $\{$ Weak, Medium, Good $\}$ & $\{0-3.5,3.2-6.5,6.2-10\}$ \\
\hline 6 & Q6 & & & \\
\hline 7 & Q7 & Practical work (I4) & $\{$ Weak, Medium, Good $\}$ & $\{0-3.5,3.2-6.5,6.2-10\}$ \\
\hline 8 & Q8 & & & \\
\hline 9 & Q9 & Data Processing (I5) & $\{$ Weak, Medium, Good $\}$ & $\{0-3.5,3.2-6.5,6.2-10\}$ \\
\hline 10 & Q10 & & & \\
\hline 11 & Q11 & Networking (I6) & $\{$ Weak, Medium, Good $\}$ & $\{0-3.5,3.2-6.5,6.2-10\}$ \\
\hline 12 & Q12 & & & \\
\hline
\end{tabular}

\subsection{Rule Evaluation}

After fuzzification process is finished, the next step is to construct fuzzy rules [22]. In this step the fuzzified inputs are taken and applied to the antecedents of the fuzzy rules. The fuzzy operator (AND or OR) must be used if a given fuzzy rule has multiple antecedents. This is done to obtain a single number that represents the result of the evaluation. The obtained number will then be applied to the following membership function. In order to evaluate the disjunction of the rule antecedents, we use the OR fuzzy operation. This OR operation can simply be customized if needed. There are many methods for the OR operation. In MATLAB fuzzy logic toolbox [23] there is two built in OR methods: max and the probabilistic OR method (probor). Probor is calculated as:

$$
\mu \mathrm{AUB}(\mathrm{X})=\operatorname{probor}[\mu \mathrm{A}(\mathrm{X}), \mu \mathrm{B}(\mathrm{X})]=\mu \mathrm{A}(\mathrm{X})+\mu \mathrm{B}(\mathrm{X})-\mu \mathrm{A}(\mathrm{X}) \mathrm{x} \mu \mathrm{B}(\mathrm{X})
$$

The fuzzy inference also supports two AND methods: min and the product, prod. The product is calculated as:

$$
\mu \mathrm{AUB}(\mathrm{X})=\operatorname{prodr}[\mu \mathrm{A}(\mathrm{X}), \mu \mathrm{B}(\mathrm{X})]=\mu \mathrm{A}(\mathrm{X}) \times \mu \mathrm{B}(\mathrm{X})
$$

Many AND and OR fuzzy operators have been proposed and applied by Fuzzy researchers. These different operators will of course lead to different results. Most of the fuzzy packages nowadays can let the user to customize the AND and OR fuzzy operations.

The result of antecedent evaluation will then can be applied to the membership function of the consequent. It means that the consequent membership function is clipped or scaled to the level of the truth value of the antecedent. Usually clipping or correlation of minimum is commonly used as it involves faster mathematics and less complex than scaling. It also generates an aggregated output surface that is easier to defuzzify. The fuzzy variable identified in this project is the type of skill, which contributes based on the grade achievement of the eight input subjects. Each of the subjects will be classified with four fuzzy outputs which are programming skill, problem solving skill, computer skill, practical work skill and decision-making skill. Thus, the each output of the rule is to identify all four type skills whether it is weak, medium or good. Table 5 shows the partial rules of the programming skills, computer skills, problem solving skills and data analyst skills.

Table 5. Linguistic variable for interest

\begin{tabular}{cl}
\hline No & \\
\hline RULE 1 & IF CSC138 is A+ \\
& AND CSC248 is C+ \\
RULE 2 & THEN programming skill is medium \\
& IF CSC204 is A+ \\
& AND ITT300 is A \\
RULE 3 & THEN computer skill is good \\
& IF CSC204 is B+ \\
& AND ITT300 is B- \\
RULE 4 & THEN computer skill is medium \\
& IF MAT233 is B+ \\
& AND QMT is C \\
RULE 5 5 & THEN problem solving skill is weak \\
& IF ITS232 is A \\
& AND ITS332 is A \\
& THEN data analyst skill is good \\
\hline
\end{tabular}

Indonesian J Elec Eng \& Comp Sci, Vol. 17, No. 1, January 2020 : 365-371 


\subsection{Aggregation}

The third step in the Mamdani style inference is the process of unification of the output yield from all of the rules. This step is known as aggregation. Normally all the membership functions which are previously clipped of scaled is combined into a single fuzzy set. Thus, the input of the aggregation process is the list of clipped or scaled consequent membership functions, and the output is one fuzzy set for each output variable.

In this case, our fuzzy inference will have four aggregated rule output representing programming skill, computer skill, problem solving skill and data analyst skill.

\subsection{Defuzzification}

Although fuzziness has help to evaluate the rules, the final output of a fuzzy system has to be a crisp number. The last step in this process is defuzzification [24]. The input for the defuzzification process is aggregated output fuzzy set and the output is a single number. Defuzzification of the aggregated fuzzy set can be done in several methods, but the most popular method is the centroid technique. The centroid technique finds a point where a vertical line would slice the aggregate set into two equal masses. The mathematical expression of the centre of gravity (COG) is as follows.

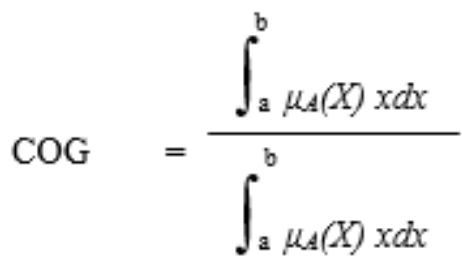

\section{RESULTS AND ANALYSIS}

The testing value for programming skill, computer skill, problem solving skill and data analyst skill respectively shown in Figures 2 and 3. The tested set of numbers inputs and the result obtained satisfied the formula. The figure shows that the output of skill and interest type is correct and the engine of the system has been running well.

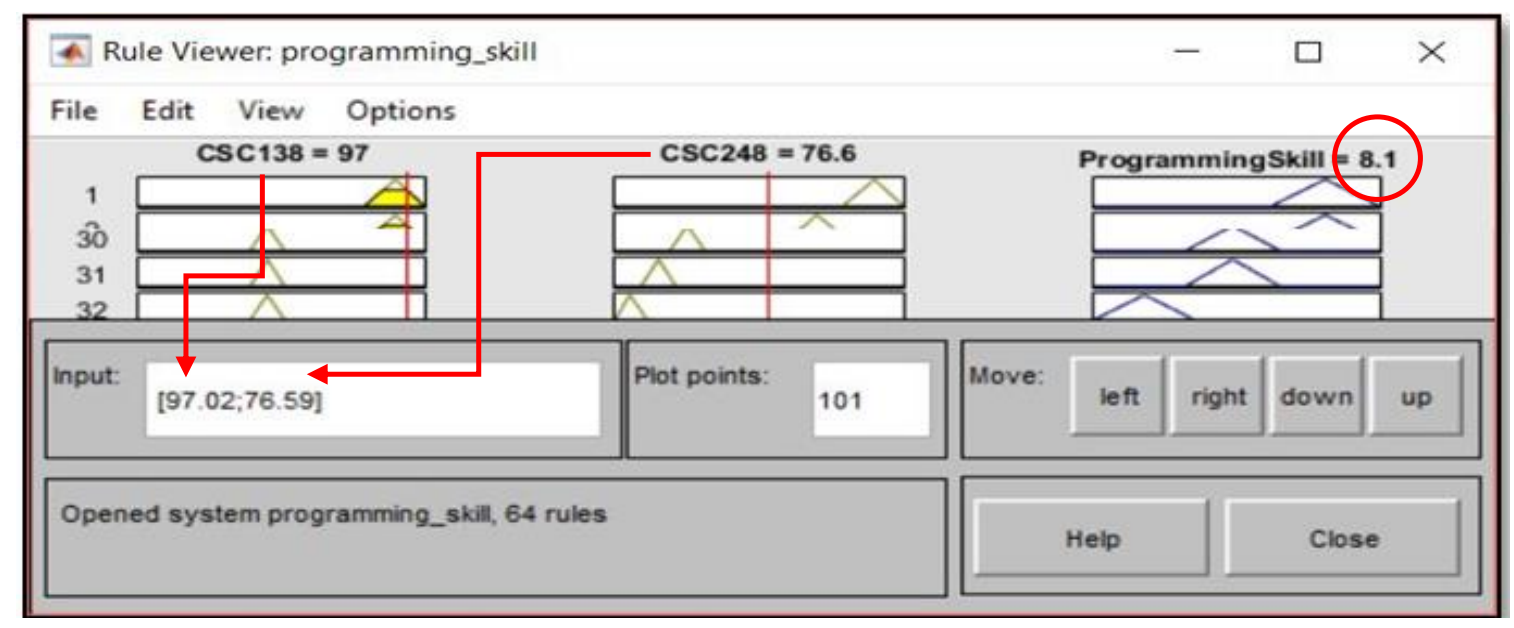

Figure 2. Testing Value for Programming Skill

\section{$\underline{\text { Programming Skill (S1) Input }}$ CSC138: $97(\mathrm{~A}+)$ CSC248: $76.6(\mathrm{~A}-)$}

Programming Skill (S1) Output Programming Skill: 8.1 (Good)

As shown in Figure 2, the result of the output value is satisfied with input values. In this figure, based on student input the value for CSC138 is $97(\mathrm{~A}+)$ and for CSC248 is $76.6(\mathrm{~A}-)$ and will get the output value is above than 6.2 , which is 8.1 . Therefore, programming skill is good. 


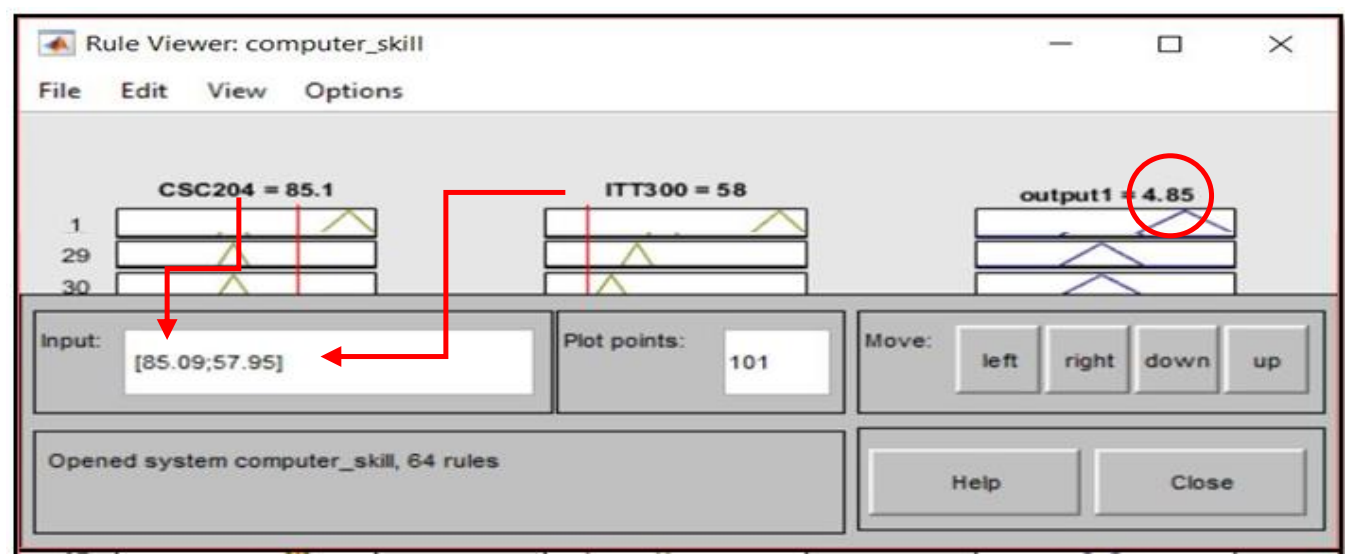

Figure 3. Testing Value for Computer Skill

\author{
Computer Skill (S3) Input \\ CSC204: 85.1 (A) \\ ITT300 : $58(\mathrm{C})$
}

\author{
Computer Skill (S3) Output \\ Computer Skill: 4.85 (Medium)
}

As shown in Figure 3, the result of the output value is satisfied with input values. In this figure, based on user input the value for CSC204 is 85.1 (A) and for ITT300 is 58 (C) and will get the output value is above 3.2 and below 6.5, which is 4.85 . Therefore, computer skill is medium.

\section{CONCLUSION}

Choosing the right course during register action for continuing study is the first key for a student to get the future success. In [25], stated that the student's interest and academic achievement are related and relevant as a cause of a student to get an excellent academic performance. A positive achievement among a sample of 50 students which are based on vigor, self-efficacy, self-set goals and previous academic result. Both personal and situational interest have the potential to influence academic achievement as well as with the use of deeper cognitive strategies [26]. Course recommendation is a system that can help the students to identify their potential, ability, skill to get the best suggestion of course that also related with their result [27].

\section{ACKNOWLEDGEMENTS}

The authors gratefully acknowledge the help of the Universiti Teknologi MARA (UiTM) for sponsoring this paper under Lestari Research Grant (600-IRMI/MyRA 5/3/LESTARI (061/2017)).

\section{REFERENCES}

[1] N. Sawarkar, M. M. Raghuwanshi, and K. R. Singh, "Intelligent Recommendation System for Higher Education," Int. J. Futur. Revolut. Comput. Sci. Commun. Eng., vol. 4, no. 4, pp. 311-320, 2018.

[2] M. Ouadoud, M. Y. Chkouri, A. Nejjari, and K. E. El Kadari, "Exploring a Recommendation System of Free Elearning Platforms: Functional Architecture of the System.," Int. J. Emerg. Technol. Learn., vol. 12, no. 2, pp. 219-226, 2017.

[3] J. Wei, J. He, K. Chen, Y. Zhou, and Z. Tang, "Collaborative filtering and deep learning based recommendation system for cold start items,” Expert Syst. Appl., vol. 69, pp. 1339-1351, 2017.

[4] R. Colomo-Palacios, F. J. García-Peñalvo, V. Stantchev, and S. Misra, "Towards a social and context-aware mobile recommendation system for tourism," Pervasive Mob. Comput., vol. 38, pp. 505-515, 2017.

[5] Parul and K. Khanna, "Literature Survey: Recommender Systems," Int. J. Eng. Technol. Manag. Appl. Sci., vol. 3, no. March, pp. 268-273, 2015.

[6] D. Yang, D. Adamson, and C. P. Rosé, "Question Recommendation with Constraints for Massive Open Online Courses," in Proceedings of the 8th ACM Conference on Recommender systems - RecSys '14, 2014, pp. 49-56.

[7] Ł. Kidziński, "SweetRS: Dataset for a recommender systems of sweets," pp. 1-2, 2017.

[8] S. Deng et al., "A Recommendation System to Facilitate Business Process Modeling," IEEE Trans. Cybern., vol. 47, no. 6, pp. 1380-1394, 2017.

[9] W. T. Chu and Y. L. Tsai, "A hybrid recommendation system considering visual information for predicting favorite restaurants," World Wide Web, vol. 20, no. 6, pp. 1313-1331, 2017. 
[10] E. van Thiel, “Career test,” 2018. [Online]. Available: https://www.123test.com/career-test/. [Accessed: 21-Jan-2018].

[11] “educations.com," 2018. [Online]. Available: https://www.educations.com/career-test. [Accessed: 18-Feb-2018].

[12] Grewal and Kaur, "Developing an Intelligent Recommendation System for Course Selection by Students for Graduate Courses," Bus. Econ. J., vol. 7, no. 2, 2015.

[13] K. Tanaka, "An Introduction to Fuzzy Logic for Practical Applications". Springer, 1996.

[14] D. Conley, "Fuzzy Logic Get Fuzzy 2". Andrews McMeel Publishing, 2002.

[15] T. J. Ross, "Fuzzy Logic with Engineering Applications". Wiley, 2010.

[16] T. R. Razak, M. A. Hashim, N. M. Noor, I. H. A. Halim, and N. F. F. Shamsul, "Career Path Recommendation System for UiTM Perlis Students Using Fuzzy Logic," in 2014 5th International Conference on Intelligent and Advanced Systems: Technological Convergence for Sustainable Future, ICIAS 2014-Proceedings, 2014.

[17] M. R. Shamsuddin, Z. Ibrahim, and A. Mohamed, "Slant classification using FuzzySIS," in 3rd International Conference on Convergence and Hybrid Information Technology, ICCIT 2008, 2008, vol. 1, pp. 1080-1085.

[18] M. S. Sulaiman and M. K. A. Ghani, "Software Requirement, Analysis \& Design, Object Oriented Approach with $U M L "$. Penerbit Universiti, Universiti Teknikal Malaysia Melaka, 2011.

[19] M. Negnevitsky, "Artificial Intelligence: A Guide to Intelligence Systems". 2005.

[20] S. Imandoost, H. S. Yazdi, and J. Haddadnia, "Image semantic retrieval using image fuzzification based on weighted relevance feedback," in 18th Iranian Conference on Electrical Engineering, 2010.

[21] Jawatankuasa Unit Kualiti, "Quality Documents," 2019.

[22] D. S. Yeung and E. C. C. Tsang, "A weighted fuzzy production rule evaluation method," in Proceedings IEEE International Conference on Fuzzy Systems., 1995.

[23] I. The MathWorks, "Fuzzy Logic Toolbox," 2019. [Online]. Available: https://au.mathworks.com/products/fuzzylogic.html.

[24] R. Ruelas, "General meaning of defuzzification," in Proceedings World Automation Congress, 2004.

[25] A. Kaklauskas et al., "Recommender System to Analyze Student's Academic Performance," Expert Syst. Appl., vol. 40, no. May, pp. 6150-6165, 2013.

[26] U. Schiefele, A. Krapp, and A. Winteler, "Interest as a predictor of academic achievement: A meta-analysis of research,” role Interes. Learn. Dev., no. November 2016, pp. 183-212, 1992.

[27] F. O. Isinkaye, Y. O. Folajimi, and B. A. Ojokoh, "Recommendation systems: Principles, methods and evaluation," Egypt. Informatics J., vol. 16, no. 3, pp. 261-273, 2015.

\section{BIOGRAPHIES OF AUTHORS}
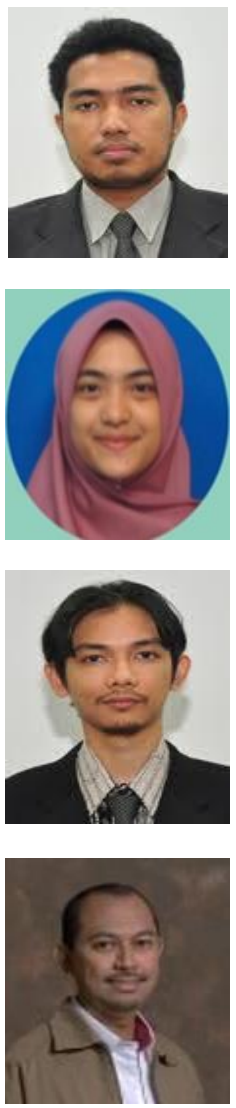

Mohd Suffian Sulaiman obtained the BSc. in Computer (Hons.) in 2002 from Universiti Teknologi Malaysia (UTM), Johor, Malaysia and MSc. in Computer Science - Real Time Software Engineering in 2004 from Universiti Teknologi Malaysia Kuala Lumpur (UTM KL). His research interest are software engineering, ontology engineering, semantic based image retrieval and data visualization.

Amylia Ahamad Tamizi obtained the BSc. in Computer Science (Hons.) in 2018 from Universiti Teknologi MARA (UiTM), Selangor, Malaysia. Her research interest are fuzzy logic, recommendation system and computer education.

Mohd Razif Shamsudin obtained the BSc. in Computer Science (Hons.) in 2005 from Universiti Teknologi MARA (UiTM), Selangor, Malaysia and MSc. in Computer Science (by research) in 2009 from Universiti Teknologi MARA (UiTM), Selangor, Malaysia. His research interest are artificial intelligent, fuzzy logic and machine learning.

Azri Azmi obtained the BSc. in Computer (Hons.) in 1996 from Universiti Teknologi Malaysia (UTM), Johor, Malaysia, MSc. in Computer Science - Real Time Software Engineering in 1998 from Universiti Teknologi Malaysia Kuala Lumpur (UTM KL) and PhD in Computer Science in 2017 from Universiti Teknologi Malaysia Kuala Lumpur (UTM KL), Malaysia. His research interests are software engineering, software testing, software traceability, software maintenance and software documentation. 